\title{
Ionic association and conductance of ionic liquids in dichloromethane at temperatures from 278.15 to $303.15 \mathrm{~K}$
}

\author{
Agnieszka Boruń $^{1} \cdot$ Adam Bald $^{1}$
}

Received: 16 September 2015 /Revised: 18 November 2015 / Accepted: 1 December 2015 /Published online: 14 January 2016

(C) The Author(s) 2016. This article is published with open access at Springerlink.com

\begin{abstract}
The electrical conductances of very dilute solutions of the ionic liquids 1-ethyl-3-methylimidazolium tetrafluoroborate $[\mathrm{emim}]\left[\mathrm{BF}_{4}\right]$ and 1-butyl-3-methylimidazolium tetrafluoroborate $[\mathrm{bmim}]\left[\mathrm{BF}_{4}\right]$ in the low-permittivity solvent dichloromethane have been measured in the temperature range from 278.15 to $303.15 \mathrm{~K}$ at $5 \mathrm{~K}$ intervals. The data was analyzed assuming the possible presence of contact (CIP) and solvent-separated (SSIP) ion pairs in the solution on the basis of 1cCM model to obtain ionic association constants, $K_{\mathrm{A}}$, and the limiting molar conductivities, $\Lambda_{\mathrm{o}}$, of these electrolytes. The examined ionic liquids are strongly associated in dichloromethane over the whole temperature range. From the temperature dependence of the limiting molar conductivities, the Eyring's activation enthalpy of charge transport was determined. The thermodynamic functions such as Gibbs energy, entropy, and enthalpy of the process of ion pair formation were calculated from the temperature dependence of the association constants.
\end{abstract}

Keywords Conductance · 1-Alkyl-3-methylimidazolium tetrafluoroborate $\cdot$ Ion association $\cdot$ Thermodynamic functions

\section{Introduction}

Creating sets of data on physical and chemical properties of ionic liquids (ILs) are of essential significance for both pure scientific and industrial purposes. The transport properties of

Agnieszka Boruń

chmielewska.a@gmail.com

1 Department of Physical Chemistry, University of Łódź, Pomorska 163, 90-236 Łódź, Poland the mixtures of ionic liquids (conductance, viscosity, and transference numbers) are important because the values provide useful and sensitive information about ion-solvent interaction, ionic association, and solvent structure. A survey of literature indicates that most studies report only the specific conductivity data for pure ionic liquids or binary and ternary mixtures of ILs with various solvents at $298.15 \mathrm{~K}$. The conductance studies of dilute solutions of ionic liquids in a wide temperature range allow the determination of the values of association constants and thermodynamic functions of association, which consequently allows the better understanding of the behavior of ILs in various solvents [1-3]. This paper is both a continuation and an extension of our and other authors' works on association of imidazolium-based ionic liquids, i.e., $[\mathrm{emim}]\left[\mathrm{BF}_{4}\right]$ and $[\mathrm{bmim}]\left[\mathrm{BF}_{4}\right]$ in water [4], 1-propanol [5], N,N-dimethylformamide [6], acetonitrile [7, 8], dimethylsulfoxide [9], and methanol [9, 10]. Moderate ionic association of ILs occurs in N,N-dimethylformamide, acetonitrile, and methanol, slight in dimethylsulfoxide, whereas it becomes significant in 1-propanol. Water promotes significantly dissociation of the ionic liquids.

According to our knowledge, conductometric data for solutions of $[\mathrm{emim}]\left[\mathrm{BF}_{4}\right]$ and $[\mathrm{bmim}]\left[\mathrm{BF}_{4}\right]$ in dichloromethane (DCM) at various temperatures have not yet been reported. The only paper is by Katsuda et al. [11], who investigated the conductance of $[\mathrm{bmim}]\left[\mathrm{BF}_{4}\right]$ in DCM exclusively at $298.15 \mathrm{~K}$. Aiming to cover this topic, the present work deals with the precise conductivity measurements, which have been carried out in the concentration range $c=0.4$ to $4 \cdot 10^{-4} \mathrm{~mol}$. $\mathrm{dm}^{-3}$ of $[\mathrm{emim}]\left[\mathrm{BF}_{4}\right]$ and $[\mathrm{bmim}]\left[\mathrm{BF}_{4}\right]$ in DCM at temperatures range $278.15-303.15 \mathrm{~K}$ at atmospheric pressure. Imidazolium-based ionic liquids were chosen because of their thermal and chemical stability and the insignificant degree of susceptibility to air and moisture. The obtained data were used to calculate the values of the limiting molar conductivities, $\Lambda_{\mathrm{o}}$, 
Table 1 Densities, $\rho_{\mathrm{o}}$, viscosities, $\eta$, and relative permittivities, $\varepsilon_{\mathrm{r}}$, of dichloromethane at different temperatures

\begin{tabular}{llll}
\hline$T / \mathrm{K}$ & $\rho_{\mathrm{o}} / \mathrm{g} \mathrm{cm}^{-3}$ & $\eta / \mathrm{mPa} \mathrm{s}[13]$ & $\varepsilon_{\mathrm{r}}[13]$ \\
\hline 278.15 & 1.352778 & 0.505 & 9.61 \\
283.15 & 1.343749 & 0.482 & 9.39 \\
288.15 & 1.334665 & 0.460 & 9.19 \\
293.15 & 1.325522 & 0.437 & 9.00 \\
298.15 & 1.316310 & 0.415 & 8.82 \\
303.15 & 1.307030 & 0.392 & 8.65 \\
\hline
\end{tabular}

and the association constants, $K_{\mathrm{A}}$ on the basis of lcCM model. The Eyring activation enthalpy of charge transport, $\Delta H_{\lambda}^{*}$, as well as the Gibbs energy, $\Delta G_{\mathrm{A}}^{\mathrm{o}}$, enthalpy, $\Delta H_{\mathrm{A}}^{\mathrm{o}}$, and entropy, $\Delta S_{\mathrm{A}}^{\mathrm{o}}$, of ion pair formation, for the electrolytes have been evaluated.

It should be stressed that measuring the conductance in the selected systems is a difficult task, since the experiments require high accuracy. It results from the fact that the relative permittivity of dichloromethane is low, its ionization properties are relatively weak, and electrolytes dissolved in DCM are strongly associated [11-15]. Therefore, it is necessary to use the extremely low concentrations of the electrolyte. For concentrations below the limit given by Fuoss [16], $c_{\max }=3.2 \cdot 10^{-7} \cdot \varepsilon_{\mathrm{r}}^{3} \mathrm{~mol}$. $\mathrm{dm}^{-3}$ (in DCM $c_{\max }=2.3 \cdot 10^{-4} \mathrm{~mol} \cdot \mathrm{dm}^{-3}$ ), it can be expected that only the free ions and ion pairs are present in the solution [17].

Table 2 Molar conductivities, $\Lambda$, corresponding molalities, $m$, and density gradients, $b$, for solutions of $[\mathrm{emim}]\left[\mathrm{BF}_{4}\right]$ and $[\mathrm{bmim}]\left[\mathrm{BF}_{4}\right]$ in $\mathrm{DCM}$ over the temperature range from 278.15 to $303.15 \mathrm{~K}$

\begin{tabular}{|c|c|c|c|c|c|c|}
\hline & $T / \mathrm{K}$ & & & & & \\
\hline & 278.15 & 283.15 & 288.15 & 293.15 & 298.15 & 303.15 \\
\hline \multicolumn{7}{|l|}{$[\mathrm{emim}]\left[\mathrm{BF}_{4}\right]$} \\
\hline & \multicolumn{6}{|c|}{$b / \mathrm{kg}^{2} \mathrm{dm}^{-3} \mathrm{~mol}^{-1}$} \\
\hline & 0.0067 & 0.0082 & 0.0100 & 0.0116 & 0.0134 & 0.0150 \\
\hline $10^{5} \mathrm{~m} / \mathrm{mol} \mathrm{kg}^{-1}$ & \multicolumn{6}{|c|}{$\Lambda / \mathrm{S} \mathrm{cm}^{2} \mathrm{~mol}^{-1}$} \\
\hline 2.9934 & 32.101 & 32.849 & 33.677 & 34.442 & 35.231 & 35.987 \\
\hline 3.0273 & 31.978 & 32.742 & 33.552 & 34.335 & 35.136 & 35.903 \\
\hline 3.7552 & 29.361 & 30.051 & 30.793 & 31.493 & 32.207 & 32.881 \\
\hline 4.4866 & 27.050 & 27.678 & 28.356 & 29.003 & 29.643 & 30.289 \\
\hline 5.4665 & 24.919 & 25.504 & 26.106 & 26.680 & 27.256 & 27.809 \\
\hline 9.5666 & 19.066 & 19.491 & 19.940 & 20.364 & 20.796 & 21.186 \\
\hline 16.047 & 15.286 & 15.626 & 15.981 & 16.313 & 16.660 & 16.980 \\
\hline 22.151 & 13.309 & 13.596 & 13.903 & 14.193 & 14.486 & 14.770 \\
\hline 29.957 & 11.617 & 11.862 & 12.126 & 12.378 & 12.632 & 12.877 \\
\hline $49.726^{\mathrm{a}}$ & 9.405 & 9.605 & 9.814 & 10.007 & 10.209 & 10.391 \\
\hline $70.244^{\mathrm{a}}$ & 8.158 & 8.329 & 8.512 & 8.689 & 8.859 & 9.024 \\
\hline $100.34^{\mathrm{a}}$ & 7.085 & 7.233 & 7.391 & 7.537 & 7.685 & 7.823 \\
\hline \multicolumn{7}{|l|}{$[\mathrm{bmim}]\left[\mathrm{BF}_{4}\right]$} \\
\hline & \multicolumn{6}{|c|}{$b / \mathrm{kg}^{2} \mathrm{dm}^{-3} \mathrm{~mol}^{-1}$} \\
\hline & -0.0183 & -0.0159 & -0.0136 & -0.0112 & -0.0080 & -0.0062 \\
\hline 3.0171 & 31.073 & 31.951 & 32.782 & 33.576 & 34.355 & 35.107 \\
\hline 3.0895 & 30.710 & 31.565 & 32.463 & 33.116 & 33.888 & 34.618 \\
\hline 3.7127 & 28.685 & 29.476 & 30.232 & 30.936 & 31.657 & 32.343 \\
\hline 4.5061 & 26.584 & 27.287 & 28.010 & 28.665 & 29.262 & 29.921 \\
\hline 5.4611 & 24.446 & 25.108 & 25.714 & 26.187 & 26.817 & 27.485 \\
\hline 9.5947 & 18.548 & 19.049 & 19.522 & 19.965 & 20.027 & 20.610 \\
\hline 14.933 & 15.344 & 15.750 & 16.131 & 16.491 & 16.820 & 17.116 \\
\hline 21.967 & 13.047 & 13.401 & 13.728 & 14.033 & 14.315 & 14.572 \\
\hline 30.573 & 11.277 & 11.573 & 11.849 & 12.101 & 12.554 & 12.704 \\
\hline $50.099^{\mathrm{a}}$ & 9.139 & 9.375 & 9.590 & 9.791 & 10.013 & 10.303 \\
\hline $70.352^{\mathrm{a}}$ & 7.956 & 8.164 & 8.350 & 8.526 & 8.715 & 8.909 \\
\hline $100.63^{\mathrm{a}}$ & 6.895 & 7.071 & 7.235 & 7.388 & 7.530 & 7.658 \\
\hline
\end{tabular}

${ }^{\mathrm{a}}$ These concentrations were not used for calculations of $\Lambda_{\mathrm{o}}$ and $K_{\mathrm{A}}$ 


\section{Experimental}

\section{Materials}

$[\mathrm{Emim}]\left[\mathrm{BF}_{4}\right]$ of $99 \%$ purity and $[\mathrm{bmim}]\left[\mathrm{BF}_{4}\right]$ of $98.5 \%$ purity were purchased from Fluka and were used as received. The water content of the studied chemicals was determined by Karl-Fischer titration. The final water mass fraction was less than $0.015 \%$ in $[\mathrm{emim}]\left[\mathrm{BF}_{4}\right]$ and $0.05 \%$ in $[\mathrm{bmim}]\left[\mathrm{BF}_{4}\right]$, respectively. Dichloromethane (minimum $99.8 \%$, water content $<0.02 \%$ ) was received from POCH Gliwice (Poland) and was used without further purification. The actual purity of DCM was estimated to be $99.97 \%$ by gas chromatography. The specific conductance, $\kappa$, of the solvent was in the range of $2-2.5 \cdot 10^{-9} \mathrm{~S} \cdot \mathrm{cm}^{-1}$ at $278.15-303.15 \mathrm{~K}$, which is in $\operatorname{good}$ agreement with available data $[11,15]$.

\section{Methods}

All the solutions were prepared by mass using an analytical balance (Sartorius RC 210D) with a precision of $\pm 1 \cdot 10^{-5} \mathrm{~g}$.

The measurement procedure was based on the method described by Bešter-Rogač et al. $[13,18]$ and used by us in our previous works $[4-6,19,20]$. Conductivity measurements were performed with a three-electrode cell with the use of a Precision Component Analyzer 6430B (Wayne-Kerr, UK) under argon atmosphere and at the different frequencies, $v,(0.2$, $0.5,1,2,3,5,10$, and 20) $\mathrm{kHz}$. The temperature was kept constant within $0.003 \mathrm{~K}$ (Calibration Thermostat UB 20F with Through-flow cooler DLK 25, Lauda, Germany). The details of the experimental procedure for conductometric measurements were described in our previous paper [6]. The estimated uncertainty of the measured values of conductivity was $0.20 \%$. The estimation of this uncertainty takes into account the high degree of difficulty associated with the conductivity measurements of electrolyte solutions in DCM. These difficulties, among others, are related to the use of very low concentrations of electrolytes and high ionic association.

Densities were measured with an Anton Paar DMA 5000M oscillating U-tube densimeter equipped with a thermostat with a temperature stability within $\pm 0.001 \mathrm{~K}$. The densimeter was calibrated with extra pure water, previously degassed ultrasonically. The estimated uncertainty of the density is $\pm 2 \cdot 10^{-4} \mathrm{~g}$. $\mathrm{cm}^{-3}$.

\section{Results and discussion}

The physical properties of dichloromethane are given in Table 1.

The measured density of DCM agreed well with those values published in the literature [13, 21, 22].
To convert molonity, $\tilde{m}$ (moles of electrolyte per kilogram of solution) into molarity, $c$, the values of density gradients, $b$, have been determined independently and used in the equation

$c / \tilde{m}=\rho=\rho_{\mathrm{o}}+b \tilde{m}$

where $\rho_{o}$ is the density of the solvent. Molar concentrations, $c$, were necessary to use the conductivity equation. The density gradients and the molar conductivities of the ILs in solution, $\Lambda$, as a function of IL molality, $m$ (moles of electrolyte per kilogram of solvent) and temperature are presented in Table 2. The relationship among $m, \tilde{m}$, and $c$ is the following

$\tilde{m}=c / \rho=m /(1+m M)$

where $M$ is the molar mass of electrolyte.

The plot of molar conductivity, $\Lambda$, versus the square root of the molar concentration, $c^{1 / 2}$, for the investigated systems monotonically decreases as shown in Figs. 1 and 2, respectively, over the temperature range from 273.15 to $303.15 \mathrm{~K}$. The values of $\Lambda$ for ionic liquids in DCM are smaller than in DMF [6], water [4], and 1-propanol [5]. With a change of temperature, they change very slightly, in contrast to the above-mentioned solvents.

The conductivity data were analyzed in the framework of the low concentration Chemical Model (lcCM) [23]. This approach uses the following set of equations

$\Lambda=\alpha\left[\Lambda_{0}-S(\alpha c)^{1 / 2}+E(\alpha c) \ln (\alpha c)+J_{1}(\alpha c)+J_{2}(\alpha c)^{3 / 2}\right]$

$K_{\mathrm{A}}=(1-\alpha) /\left(\alpha^{2} c y_{ \pm}^{2}\right)$

and

$\ln y_{ \pm}=-\left(A \alpha^{1 / 2} c^{1 / 2}\right) /\left(1+B R \alpha^{1 / 2} c^{1 / 2}\right)$

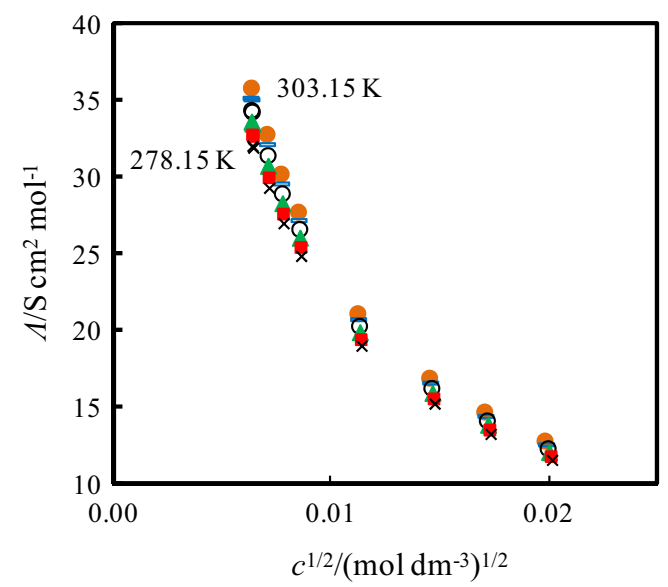

Fig. 1 Molar conductivity, $\Lambda$, of $[\mathrm{emim}]\left[\mathrm{BF}_{4}\right]$ solutions in DCM versus $c^{1 / 2}$ at experimental temperatures; $\times 278.15 \mathrm{~K}, \square 283.15 \mathrm{~K}, \triangle 288.15 \mathrm{~K}$, ○ $293.15 \mathrm{~K},-298.15 \mathrm{~K}, 303.15 \mathrm{~K}$ 


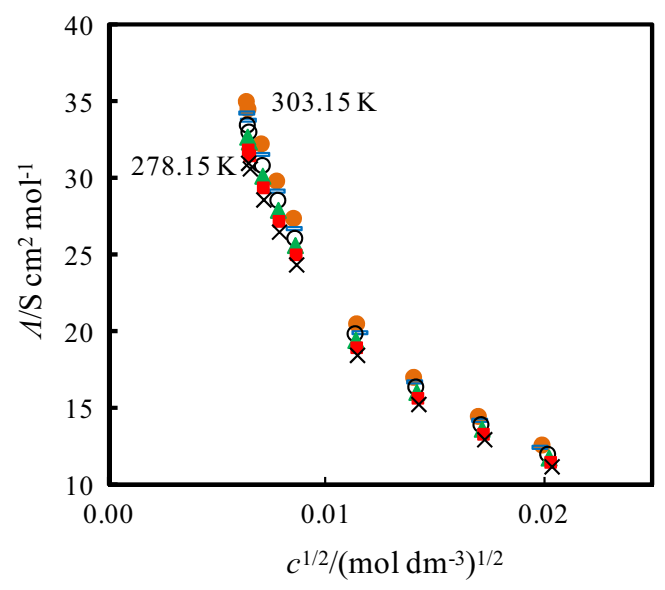

Fig. 2 Molar conductivity, $\Lambda$, of $[\mathrm{bmim}]\left[\mathrm{BF}_{4}\right]$ solutions in $\mathrm{DCM}$ versus $c^{1 / 2}$ at experimental temperatures; $\times 278.15 \mathrm{~K}, \square 283.15 \mathrm{~K}, \triangle 288.15 \mathrm{~K}$, ○ $293.15 \mathrm{~K},-298.15 \mathrm{~K}, \bullet 303.15 \mathrm{~K}$

In these equations, $\Lambda_{\mathrm{o}}$ is the limiting molar conductivity, $\alpha$ is the dissociation degree of an electrolyte, $K_{\mathrm{A}}$ is the ionic association constant, $R$ is the distance parameter of ions, $y_{ \pm}$ is the activity coefficient of ions on the molar scale, and $A$ and $B$ are the Debye-Hückel equation coefficients. The analytical form of the parameters $S, E, J_{1}$, and $J_{2}$ was presented previously [23].

In all previous papers [4-6, 19, 20], the values of $\Lambda_{\mathrm{o}}, K_{\mathrm{A}}$, and $R$ were obtained using the well-known procedure given by Fuoss [24]. However, in this case, we were unable to optimize the values of $R$ in a sufficiently reliable manner. Therefore, we calculated the values of $R$ independently, assuming the possible existence of contact (CIP) and solvent-separated (SSIP) ion pairs in the solution. For this purpose, the distance of closest approach (contact distance) of cation and anion,
$R=a=a_{+}+a_{-}$, we calculated from the ionic radius of $\mathrm{BF}_{4}{ }^{-}$, $a_{-}=0.227$ and $a_{+}=0.331 \mathrm{~nm}$ for $[\mathrm{bmim}]^{+}$and $a_{+}=0.310 \mathrm{~nm}$ for $[\mathrm{emim}]^{+}[11]$. The latest value was extrapolated by us from the radii of ions $[\mathrm{bmim}]^{+},[\mathrm{hmim}]^{+}$, and $[\mathrm{omim}]^{+}[11]$. In the case of solvent-separated ion pair, $R=a+s$, where $s$ is the length of an orientated solvent molecule, we assumed according to $[13,25] s=0.177 \mathrm{~nm}$. The results obtained by a twoparameter fit $\left(\Lambda_{\mathrm{o}}\right.$ and $\left.K_{\mathrm{A}}\right)$ are collected in Table 3. For the last three concentrations from Table 2, the calculated values of $\Lambda$ were lower than the experimental ones. Moreover, the differences between calculated and experimental values of $\Lambda$ increase with an increase of concentration. This suggests that in solution form higher aggregates such as triple ion formation. Therefore, we did not use the last three concentrations for calculations, and we used a range of concentrations ( $c=0.4$ to $4 \cdot 10^{-4} \mathrm{~mol} \cdot \mathrm{dm}^{-3}$ ) consistent with the Fuoss condition [16].

As seen from Table 3, the limiting molar conductivities increase as the temperature increases since the mobility of free ions is higher. The values of $\Lambda_{\mathrm{o}}$ for [emim] $\left[\mathrm{BF}_{4}\right]$ are higher compared to those values for $[\mathrm{bmim}]\left[\mathrm{BF}_{4}\right]$ because the $\Lambda_{\mathrm{o}}$ values increase with decreasing alkyl chain length of the ILs. Furthermore, the differences between the $\Lambda_{\mathrm{o}}$ values for both ionic liquids increase with increasing temperature. The limiting molar conductivities for $[\mathrm{emim}]\left[\mathrm{BF}_{4}\right]$ and [bmim] $\left[\mathrm{BF}_{4}\right]$ presented in Table 3 are much higher than corresponding values determined in 1-propanol, DMF, and water [4-6]. However, one should pay attention to the fact that the determining factor that affects the $\Lambda_{\mathrm{o}}$ value, a macroscopic viscosity of the solvent, in the case of dichloromethane, is very small (see Table 1). The value of $\Lambda_{\mathrm{o}}$ for $[\mathrm{bmim}]\left[\mathrm{BF}_{4}\right]$ at $298.15 \mathrm{~K}$ is in good agreement with this reported by Katsuta et al. [11] $\left(\Lambda_{\mathrm{o}}=162.5 \mathrm{~S} \mathrm{~cm}^{2} \mathrm{~mol}^{-1}\right)$. Obtained values of standard deviations, $\sigma(\Lambda)$, may be considered to be high, but
Table 3 Limiting molar conductivities, $\Lambda_{\mathrm{o}}$, association constants, $K_{\mathrm{A}}$, and standard deviations, $\sigma(\Lambda)$, for the investigated electrolytes in DCM at different temperature

\begin{tabular}{ccccccc}
\hline$T / \mathrm{K}$ & $\begin{array}{l}\Lambda_{\mathrm{o}} / \mathrm{S} \mathrm{cm}^{2} \mathrm{~mol}^{-1} \\
\mathrm{CIP}\end{array}$ & $K_{\mathrm{A}} / \mathrm{dm}^{3} \mathrm{~mol}^{-1}$ & $\sigma(\Lambda)$ & $\begin{array}{l}\Lambda_{\mathrm{o}} / \mathrm{S} \mathrm{cm}^{2} \mathrm{~mol}^{-1} \\
\mathrm{SSSIP}\end{array}$ & $K_{\mathrm{A}} / \mathrm{dm}^{3} \mathrm{~mol}^{-1}$ & $\sigma(\Lambda)$ \\
\hline $\begin{array}{c}{[\mathrm{emim}]\left[\mathrm{BF}_{4}\right]} \\
278.15\end{array}$ & 149.74 & 467,030 & 0.13 & 151.20 & 477,780 & 0.13 \\
283.15 & 156.39 & 491,840 & 0.13 & 157.78 & 502,200 & 0.13 \\
288.15 & 164.56 & 525,200 & 0.13 & 166.07 & 536,530 & 0.13 \\
293.15 & 172.51 & 558,210 & 0.14 & 173.82 & 568,340 & 0.14 \\
298.15 & 181.07 & 595,110 & 0.14 & 182.96 & 609,480 & 0.14 \\
303.15 & 190.63 & 640,300 & 0.15 & 192.41 & 654,130 & 0.15 \\
{$[\mathrm{bmim}][\mathrm{BF} 4]$} & & & & & \\
278.15 & 136.49 & 402,980 & 0.20 & 137.65 & 411,280 & 0.20 \\
283.15 & 142.24 & 418,760 & 0.20 & 143.54 & 427,990 & 0.20 \\
288.15 & 147.93 & 434,990 & 0.20 & 149.72 & 447,400 & 0.20 \\
293.15 & 155.01 & 463,310 & 0.20 & 156.26 & 473,640 & 0.20 \\
298.15 & 161.08 & 478,920 & 0.13 & 162.56 & 489,420 & 0.13 \\
303.15 & 168.50 & 510,440 & 0.22 & 170.18 & 522,420 & 0.22 \\
\hline
\end{tabular}


Table 4 Comparison of limiting molar conductivities, $\Lambda_{\mathrm{o}}$, association constants, $K_{\mathrm{A}}$, and Gibbs-free energy $\Delta G_{\mathrm{A}}^{\mathrm{o}}$, for solutions of $[\mathrm{emim}]\left[\mathrm{BF}_{4}\right]$ and $[\mathrm{bmim}]\left[\mathrm{BF}_{4}\right]$ in various molecular solvents of viscosity, $\eta$, and relative permittivity, $\varepsilon_{\mathrm{r}}$, at $298.15 \mathrm{~K}$

\begin{tabular}{|c|c|c|c|c|c|c|}
\hline Solvent & $\eta / \mathrm{mPa} \mathrm{s}$ & $\varepsilon_{\mathrm{r}}$ & $\Lambda_{\mathrm{o}} / \mathrm{S} \mathrm{cm}^{2} \mathrm{~mol}^{-1}$ & $K_{\mathrm{A}} / \mathrm{dm}^{3} \mathrm{~mol}^{-1}$ & $\Delta G_{\mathrm{A}}^{\mathrm{o}} / \mathrm{kJ} \mathrm{mol}^{-1}$ & Ref. \\
\hline \multirow[t]{2}{*}{ DCM } & \multirow[t]{2}{*}{0.415 [13] } & \multirow[t]{2}{*}{8.82 [10] } & $181.07^{a}$ & $595,110^{a}$ & -33.0 & $c$ \\
\hline & & & $161.08^{b}$ & $478,920^{b}$ & -32.4 & $c$ \\
\hline \multirow[t]{2}{*}{$\mathrm{PrOH}$} & \multirow[t]{2}{*}{$1.957[5]$} & \multirow[t]{2}{*}{$20.45[26]$} & $31.43^{a}$ & $943^{a}$ & -17.0 & [5] \\
\hline & & & $30.29^{b}$ & $987^{b}$ & -17.1 & [5] \\
\hline \multirow[t]{3}{*}{$\mathrm{MeOH}$} & \multirow[t]{3}{*}{$0.5438[9]$} & \multirow[t]{3}{*}{32.63 [9] } & $134.0^{a}$ & $66.1^{a}$ & -10.4 & [10] \\
\hline & & & $121.84^{b}$ & $37.7^{b}$ & -9.0 & [9] \\
\hline & & & $126.9^{b}$ & $53.7^{b}$ & -9.9 & [10] \\
\hline \multirow[t]{4}{*}{$\mathrm{ACN}$} & \multirow[t]{4}{*}{$0.3413[13]$} & \multirow[t]{4}{*}{35.96 [7] } & $197.10^{a}$ & $15.9^{a}$ & -6.9 & [7] \\
\hline & & & $198.3^{a}$ & $17.9^{a}$ & -7.2 & [8] \\
\hline & & & $189.29^{b}$ & $15.7^{b}$ & -6.8 & [7] \\
\hline & & & $190.3^{b}$ & $18.2^{b}$ & -7.2 & [8] \\
\hline \multirow[t]{2}{*}{$\mathrm{DMF}$} & \multirow[t]{2}{*}{$0.8455[6]$} & \multirow[t]{2}{*}{$36.81[27]$} & $93.47^{a}$ & $11.30^{a}$ & -6.0 & {$[6]$} \\
\hline & & & $89.83^{b}$ & $10.57^{b}$ & -5.9 & {$[6]$} \\
\hline DMSO & 1.9946 [9] & 46.52 [9] & $41.51^{b}$ & $4.6^{b}$ & -3.8 & [9] \\
\hline \multirow[t]{2}{*}{ Water } & \multirow[t]{2}{*}{$0.8903[26]$} & \multirow[t]{2}{*}{$78.36[27]$} & $114.27^{a}$ & $0.89^{a}$ & & [4] \\
\hline & & & $107.39^{b}$ & $016^{b}$ & & [4] \\
\hline
\end{tabular}

${ }^{a}[\mathrm{Emim}]\left[\mathrm{BF}_{4}\right]$

${ }^{b}[\mathrm{Bmim}]\left[\mathrm{BF}_{4}\right]$

${ }^{c}$ This paper should be noted that the conductometric measurements of analyzed systems are very difficult to be performed.

From data collected in Table 4 for investigated ILs in various solvents results that the values of limiting molar conductivities, $\Lambda_{\mathrm{o}}$, follow the order: acetonitrile $>$ dichloromethane $>$ methanol $>$ water $>$ N,N-dimethylformamide $>$ dimethyl sulfoxide $>1$-propanol. As mentioned above, the conductivity increase is related to the decrease in solvent viscosity. However, for the series given above, this relationship is not entirely fulfilled. But if we consider the protic and aprotic character of solvents, the conductivity decreases in the order: $\mathrm{MeOH}>$ Water $>1-\mathrm{PrOH}$, and for aprotic: $\mathrm{ACN}>\mathrm{DCM}>\mathrm{DMF}>\mathrm{DMSO}$, which correlates very well with viscosity increase.

It is observed from Table 3 that both ionic liquids are very highly associated in DCM. This observation stays in agreement with literature data for various imidazolium ILs in DCM $\left(\mathrm{K}_{\mathrm{A}} \approx 1 \cdot 10^{4}-38 \cdot 10^{4} \mathrm{dm}^{3} \mathrm{~mol}^{-1}\right)[11,13]$. The value of $K_{\mathrm{A}}=384300 \mathrm{dm}^{3} \mathrm{~mol}^{-1}$ for $[\mathrm{bmim}]\left[\mathrm{BF}_{4}\right]$ in DCM at $298.15 \mathrm{~K}$ presented in paper [11] is slightly lower than ours. This can be explained by different procedure used for experimental data analysis and the different measuring procedure. As we can see from the Table $3, K_{\mathrm{A}}$ values depend significantly on the adopted model of ion pairs. In the case of solvent-separated (SSIP) ion pairs, the $K_{\mathrm{A}}$ and $\Lambda_{\mathrm{o}}$ values are higher. The data collected in Table 3 also show that the association constants increase with increasing temperature, and the effect is much more pronounced in the case of
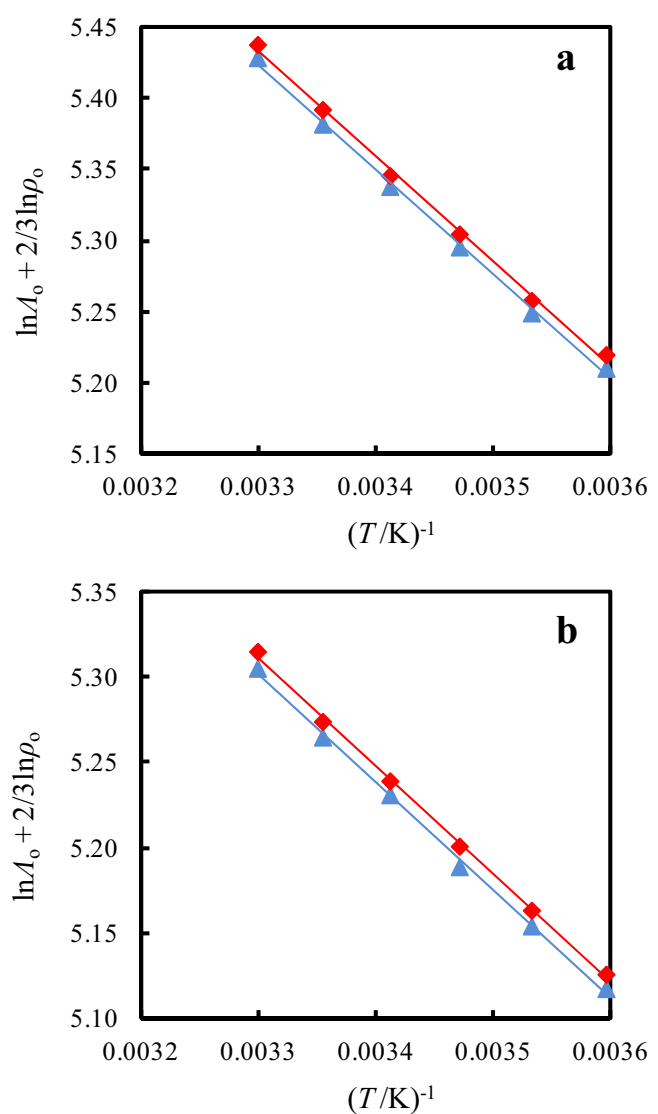

Fig. 3 a, b Plot of $\ln \Lambda_{\mathrm{o}}+2 / 3 \ln \rho_{o}$ as a function of $1 / T$ for $\mathbf{a}$ [emim] $\left[\mathrm{BF}_{4}\right]$ and $\mathbf{b}[\mathrm{bmim}]\left[\mathrm{BF}_{4}\right]$ in DCM: $(\triangle), \mathrm{CIP}$, and $(\bullet), \operatorname{SSIP}$ 
Table 5 Coefficients of Eq. (7) and correlation coefficients, $r^{2}$, for [emim] $\left[\mathrm{BF}_{4}\right]$ and [bmim $]\left[\mathrm{BF}_{4}\right]$ in DCM

\begin{tabular}{|c|c|c|c|c|c|}
\hline & & $A / \mathrm{kJ} \mathrm{mol}^{-1}$ & $B / \mathrm{J} \mathrm{mol}^{-1} \mathrm{~K}^{-1}$ & $C / \mathrm{J} \mathrm{mol}^{-1} \mathrm{~K}^{-2}$ & $r^{2}$ \\
\hline$[\mathrm{emim}]\left[\mathrm{BF}_{4}\right]$ & CIP & -14.656 & 21.71 & -0.279 & 0.99998 \\
\hline$[\mathrm{bmim}]\left[\mathrm{BF}_{4}\right]$ & & -15.556 & 21.70 & -0.263 & 0.99984 \\
\hline$[\mathrm{emim}]\left[\mathrm{BF}_{4}\right]$ & SSIP & -17.338 & 39.99 & -0.311 & 0.99998 \\
\hline$[\mathrm{bmim}]\left[\mathrm{BF}_{4}\right]$ & & -11.815 & -4.16 & -0.219 & 0.99987 \\
\hline
\end{tabular}

[emim] $\left[\mathrm{BF}_{4}\right]$. This can be due to decrease in ILs-DCM interactions with increasing temperature.

In the case of $\left[\mathrm{emim}^{-}\left[\mathrm{BF}_{4}\right]\right.$ and bmim] $\left[\mathrm{BF}_{4}\right]$ solutions in dimethyl sulfoxide [9] and N,N-dimethylformamide [6], the association constants are practically negligible; in methanol and acetonitrile [7-10], ion association is rather weak. In turn, in water [4], both ionic liquids are practically fully dissociated, whereas in 1-propanol [5] and especially in dichloromethane, they were definitely associated. The data are consistent with the classical ionic association theory of electrolytes [28]. Similar behavior of other ionic liquids in various solvents was also observed [1, 3, 29-34]. In turn, in very low-permittivity tetrahydrofuran $\left(\varepsilon_{\mathrm{r}}=7.58\right)$, ionic liquid (1-butyl-2,3-dimethylimidazolium tetrafluoroborate $[\mathrm{bmmim}]\left[\mathrm{BF}_{4}\right]$ ) form not only ion pairs but also triple ions [29]. It means that ions are more associated in the solvent possessing a low-relative permittivity. However, not only the relative permittivity of the solvent plays an essential role in the ionic association process, but also the participation of the ion-solvent interactions and the alkyl chain length of the ILs should be considered too.
From the temperature dependence of $\Lambda_{0}$, the Eyring activation enthalpy of charge transport, $\Delta H_{\lambda}^{*}$, was obtained by using Eq. 5

$\ln \Lambda_{\mathrm{o}}+2 / 3 \ln \rho_{o}=-\Delta H_{\lambda}^{*} / \mathrm{RT}+D$

where $D$ is an empirical constant. From the slope of the linear dependencies of $\ln \Lambda_{\mathrm{o}}+2 / 3 \ln \rho_{o}$ versus the inverse of the temperature $(1 / T)$, which are shown in Fig. 3(a, b), we obtained the following $\Delta H_{\lambda}^{*}$ values 6,138 (CIP) and 6,142 (SSIP) for [emim] $\left[\mathrm{BF}_{4}\right]$ and 5,257 (CIP) and 5,271 (SSIP) for [bmim $]\left[\mathrm{BF}_{4}\right]$ (all in $\mathrm{J} \cdot \mathrm{mol}^{-1}$ ), respectively. For [emim] $\left[\mathrm{BF}_{4}\right]$, the value of $\Delta H_{\lambda}^{*}$ is thus higher than [bmim] $\left[\mathrm{BF}_{4}\right]$ by 881 (CIP) and 871 (SSIP) units. It is somewhat surprising, considering the fact that in other solvents [4-7, 9], the values of $\Delta H_{\lambda}^{*}$ are higher for $[\mathrm{bmim}]\left[\mathrm{BF}_{4}\right]$ than $[\mathrm{emim}]\left[\mathrm{BF}_{4}\right]$. It is the result of the presence of a larger substituent in the $[\mathrm{bmim}]^{+}$cation compared to $[\mathrm{emim}]^{+}$. In the case of dichloromethane, it may suggest that the effective ionic radius of $[\mathrm{emim}]^{+}$is larger than the $[\mathrm{bmim}]^{+}$. Taking into account the values of the Eyring activation enthalpy of charge transport for other solvents, we
Table 6 Thermodynamic functions of association of $[\mathrm{emim}]\left[\mathrm{BF}_{4}\right]$ and $[\mathrm{bmim}]\left[\mathrm{BF}_{4}\right]$ solutions in DCM at different temperatures

\begin{tabular}{|c|c|c|c|c|c|c|}
\hline$T / \mathrm{K}$ & $\begin{array}{l}\Delta G_{\mathrm{A}}^{\mathrm{o}} \\
\mathrm{J} \mathrm{mol}^{-1} \\
\mathrm{CIP}\end{array}$ & $\begin{array}{l}\Delta S_{\mathrm{A}}^{\mathrm{o}} \\
\mathrm{J} \mathrm{mol}^{-1} \mathrm{~K}^{-1}\end{array}$ & $\begin{array}{l}\Delta H_{\mathrm{A}}^{\mathrm{o}} \\
\mathrm{J} \mathrm{mol}^{-1}\end{array}$ & $\begin{array}{l}\Delta G_{\mathrm{A}}^{\mathrm{o}} \\
\mathrm{J} \mathrm{mol}^{-1} \\
\mathrm{SSIP}\end{array}$ & $\begin{array}{l}\Delta S_{\mathrm{A}}^{\mathrm{o}} \\
\mathrm{J} \mathrm{mol}^{-1} \mathrm{~K}^{-1}\end{array}$ & $\begin{array}{l}\Delta H_{\mathrm{A}}^{\mathrm{o}} \\
\mathrm{J} \mathrm{mol}^{-1}\end{array}$ \\
\hline \multicolumn{7}{|c|}{$[\mathrm{emim}]\left[\mathrm{BF}_{4}\right]$} \\
\hline 278.15 & $-30,190$ & 133.4 & 6,910 & $-30,240$ & 132.7 & 6,690 \\
\hline 283.15 & $-30,850$ & 136.2 & 7,700 & $-30,900$ & 135.9 & 7,560 \\
\hline 288.15 & $-31,560$ & 138.9 & 8,490 & $-31,610$ & 139.0 & 8,440 \\
\hline 293.15 & $-32,250$ & 141.7 & 9,300 & $-32,300$ & 142.1 & 9,345 \\
\hline 298.15 & $-32,960$ & 144.5 & 10,130 & $-33,020$ & 145.2 & 10,260 \\
\hline 303.15 & $-33,700$ & 147.3 & 10,960 & $-33,750$ & 148.3 & 11,200 \\
\hline \multicolumn{7}{|c|}{$[\mathrm{bmim}]\left[\mathrm{BF}_{4}\right]$} \\
\hline 278.15 & $-29,850$ & 124.4 & 4,770 & $-29,890$ & 125.8 & 5,110 \\
\hline 283.15 & $-30,470$ & 127.1 & 5,510 & $-30,530$ & 128.0 & 5,720 \\
\hline 288.15 & $-31,100$ & 129.7 & 6,260 & $-31,170$ & 130.2 & 6,350 \\
\hline 293.15 & $-31,800$ & 132.3 & 7,020 & $-31,850$ & 132.4 & 6,980 \\
\hline 298.15 & $-32,420$ & 135.0 & 7,800 & $-32,480$ & 134.6 & 7,630 \\
\hline 303.15 & $-33,130$ & 137.6 & 8,590 & $-33,180$ & 136.8 & 8,280 \\
\hline
\end{tabular}


can conclude that $\Delta H_{\lambda}^{*}$ depends mainly on the solvent. In the case of protic solvents (water and 1-propanol) values are very similar (about $16,000 \mathrm{~J} \cdot \mathrm{mol}^{-1}$ ) and almost twice or more higher than those for DMF, DCM, and ACN. It can be concluded that the value of $\Delta H_{\lambda}^{*}$ depends on the formation of hydrogen bonds between molecules of the solvent and its structure.

The temperature dependence of the association constant was used to calculation of Gibbs-free energy of ion formation, $\Delta G_{\mathrm{A}}^{o}$

$\Delta G_{\mathrm{A}}^{\mathrm{o}}(T)=-R T \ln K_{\mathrm{A}}(T)$

$\Delta G_{\mathrm{A}}^{\mathrm{o}}(T)$ can also be expressed by the polynomial

$\Delta G_{\mathrm{A}}^{\mathrm{o}}(T)=A+B T+C T^{2}$

The values of parameters $A, B$, and $C$ of Eq. (7) and correlation coefficients, $r^{2}$, are summarized in Table 5 .

The entropy and enthalpy of ion association are defined as

$\Delta S_{\mathrm{A}}^{\mathrm{o}}=-\left(\partial \Delta G_{\mathrm{A}}^{\mathrm{o}} / \partial T\right)_{p}=-B-2 C T$

$\Delta H_{\mathrm{A}}^{\mathrm{o}}=\Delta G_{\mathrm{A}}^{\mathrm{o}}+T \Delta S_{\mathrm{A}}^{\mathrm{o}}=A-C T^{2}$

The thermodynamic functions of the ion pair formation $\left(\Delta G_{\mathrm{A}}^{\mathrm{o}}, \Delta S_{\mathrm{A}}^{\mathrm{o}}, \Delta H_{\mathrm{A}}^{\mathrm{o}}\right)$ at different temperatures are presented in Table 6 and in Figs. 4, 5, and 6, respectively.

The values of $\Delta G_{\mathrm{A}}^{\mathrm{o}}$ presented in Table 6 and Fig. 4 indicate that the spontaneity of the ion pair formation in the case of both ionic liquids is comparable. The increase of temperature leads to more negative $\Delta G_{\mathrm{A}}^{\mathrm{o}}$ values, which means shifting the equilibrium toward the formation of ion pairs due to reduction in preferential solvation of ions by temperature (interactions

$\mathrm{T} / \mathrm{K}$

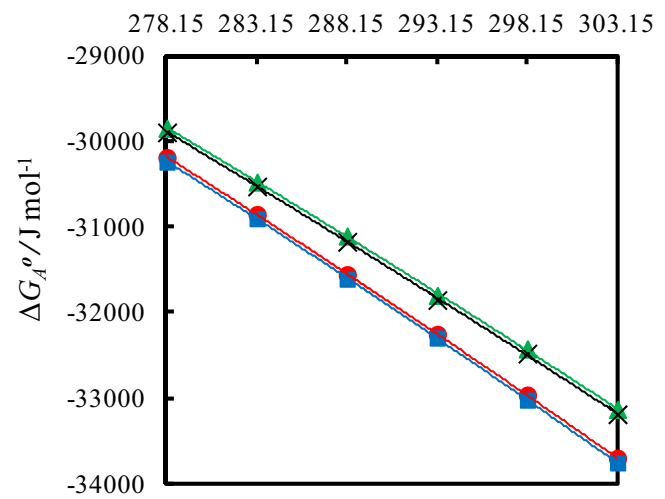

Fig. 4 Variation of Gibbs-free energy, $\Delta G_{\mathrm{A}}^{\mathrm{o}}$, as a function of temperature $T$ of $[\mathrm{emim}]\left[\mathrm{BF}_{4}\right]:(\square), \mathrm{SSIP},(\bullet), \mathrm{CIP}$, and $\left[\mathrm{bmim}^{-}\left[\mathrm{BF}_{4}\right]\right.$ in DCM, (X), $\operatorname{SSIP},(\Lambda), \mathrm{CIP}$

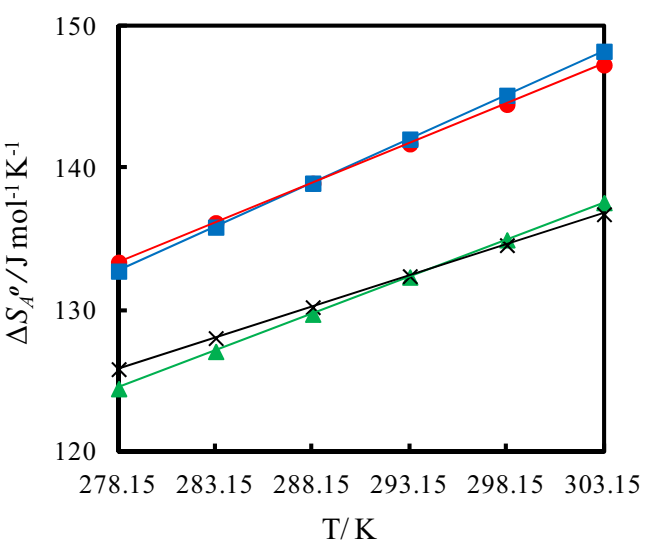

Fig. 5 Variation of association entropies, $\Delta S_{\mathrm{A}}^{\mathrm{o}}$, as a function of temperature of $[\mathrm{emim}]\left[\mathrm{BF}_{4}\right],(\square), \operatorname{SSIP},(\bullet), \mathrm{CIP}$, and $[\mathrm{bmim}]\left[\mathrm{BF}_{4}\right]$ in DCM, (X), SSIP, ( $\mathbf{\Lambda})$ CIP

between IL and DCM become weaker with increasing temperature).

The data collected in Table 4 show that the values of Gibbsfree energy of the studied ILs in other solvents are also negative (and become more negative as temperature increases).

As can be seen in Figs. 5 and 6, both the values of entropy and enthalpy of association are positive and greater for $[\mathrm{emim}]\left[\mathrm{BF}_{4}\right]$. Moreover, the values of $\Delta S_{\mathrm{A}}^{\mathrm{o}}$ and $\Delta H_{\mathrm{A}}^{\mathrm{o}}$ increase with increasing temperature for both tested electrolytes. Positive values of entropy prove that the transition from the free solvated ions into the ion pairs causes that system becomes less ordered. This is related to the partial desolvation of ions prior to the formation of ion pair. The positive values of $\Delta H_{\mathrm{A}}^{\mathrm{o}}$ indicate that the ion pair-forming processes are endothermic, particularly in the case of $[\mathrm{emim}]\left[\mathrm{BF}_{4}\right]$. From Eq. (10)

$\Delta G_{\mathrm{A}}^{\mathrm{o}}(T)=\Delta H_{\mathrm{A}}^{\mathrm{o}}(T)-T \Delta S_{\mathrm{A}}^{\mathrm{o}}(T)$

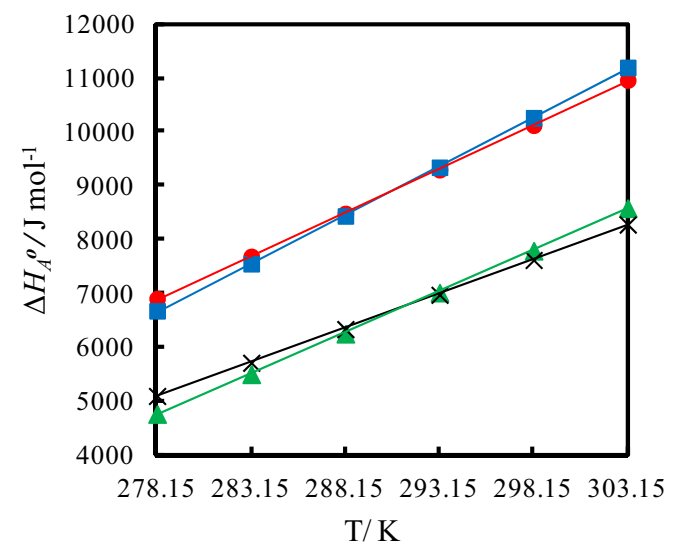

Fig. 6 Variation of enthalpies, $\Delta H_{\mathrm{A}}^{\mathrm{o}}$, as a function of temperature of $[\mathrm{emim}]\left[\mathrm{BF}_{4}\right],(\square), \mathrm{SSIP},(\bullet), \mathrm{CIP}$ and $[\mathrm{bmim}]\left[\mathrm{BF}_{4}\right]$ in DCM, (X), SSIP, (入) CIP 
it follows that entropic effects seem to dominate over the enthalpic effects because the Gibbs-free energy, $\Delta G_{\mathrm{A}}^{\mathrm{o}}$, is negative, and thus the ion pair formation is spontaneous in both cases. Furthermore, earlier studies [4-7, 19] confirm that in the case of other solvents, spontaneity of ionic association process results mainly from changes of the entropy.

\section{Conclusions}

Molar conductivities of very dilute solutions of 1-ethyl-3methylimidazolium tetrafluoroborate and 1-butyl-3methylimidazolium tetrafluoroborate in dichloromethane have been reported for the first time at $T=278.15$ to $303.15 \mathrm{~K}$. Conductivity data were analyzed using the Barthel's low concentration Chemical Model (lcCM). The examined ionic liquids act like very weak electrolytes $\left(K_{\mathrm{A}} \approx 60\right.$. $10^{4} \mathrm{~mol}^{-1} \mathrm{dm}^{3}$ for $[\mathrm{emim}]\left[\mathrm{BF}_{4}\right]$ and $\approx 48 \cdot 10^{4} \mathrm{~mol}^{-1} \mathrm{dm}^{3}$ for [bmim $]\left[\mathrm{BF}_{4}\right]$, respectively) in the low-permittivity solvent DCM at used temperature range. With increasing temperature, the tendency to form the ion pairs increases. $[\mathrm{Emim}]\left[\mathrm{BF}_{4}\right]$ is more associated electrolyte than $[\mathrm{bmim}]\left[\mathrm{BF}_{4}\right] . K_{\mathrm{A}}$ values depend significantly on the adopted model of ion pairs, (CIP) or (SSIP). The values of $\Lambda$ for ionic liquids in DCM are smaller than in DMF [6], water [4], and 1-propanol [5] and change very slightly with a change of temperature. In turn, $\Lambda_{\mathrm{o}}$ values are much higher than corresponding values determined in 1propanol, DMF, and water. The evaluated values of thermodynamic functions of association suggest the spontaneity of the association process. The values of $\Delta H_{\mathrm{A}}^{\mathrm{o}}$ are positive and suggest that the ion-pairing process is endothermic. Because the Gibbs-free energy is negative, entropic effects seem to dominate over the enthalpic effects, and thus, the ion pair formation of ionic liquids in DCM is spontaneous in both cases.

Open Access This article is distributed under the terms of the Creative Commons Attribution 4.0 International License (http:// creativecommons.org/licenses/by/4.0/), which permits unrestricted use, distribution, and reproduction in any medium, provided you give appropriate credit to the original author(s) and the source, provide a link to the Creative Commons license, and indicate if changes were made.

\section{References}

1. Luo J, Hu J, Saak W, Beckhaus R, Wittstock G, Vankelecom IFJ, Agert C, Conrad O (2011) Protic ionic liquid and ionic melts prepared from methanesulfonic acid and 1H-1,2,4-triazole as high temperature PEMFC electrolytes. J Mater Chem 21:10426-10436

2. Luo J, Tan TV, Conrad O, Vankelecom IF (2012) 1H-1,2,4-Triazole as solvent for imidazolium methanesulfonate. Phys Chem Chem Phys 14:11441-11447
3. Luo J, Conrad O, Vankelecom IFJ (2013) Imidazolium methanesulfonate as a high temperature proton conductor. $\mathrm{J}$ Mater Chem A 1:2238-2247

4. Borun A, Fernandez C, Bald A (2015) Conductance studies of aqueous ionic liquids solutions [emim] [BF4] and [bmim] [BF4] at temperatures from (283.15 to 318.15$) \mathrm{K}$. Int J Electrochem Sci 10: 2120-2129

5. Borun A, Bald A (2014) Conductometric studies of 1-ethyl-3methylimidazolium tetrafluoroborate and 1-butyl-3methylimidazolium tetrafluoroborate in 1-propanol at temperatures from (283.15 to 318.15) K. Int J Electrochem Sci 9:2790-2804

6. Boruń A, Bald A (2012) Conductometric studies of 1-ethyl-3methylimidazolium tetrafluoroborate and 1-butyl-3methylimidazolium tetrafluoroborate in $\mathrm{N}, \mathrm{N}$-dimethylformamide at temperatures from (283.15 to 318.15 ) K. J Chem Eng Data 57: 475-481

7. Bešter-Rogač M, Stoppa A, Buchner R (2014) Ion association of imidazolium ionic liquids in acetonitrile. Phys Chem B 118:14261435

8. Kalugin ON, Voroshylova IV, Riabchunova AV, Lukinova EV, Chaban VV (2013) Conductometric study of binary systems based on ionic liquids and acetonitrile in a wide concentration range. Electrochim Acta 105:188-199

9. Bešter-Rogač M, Hunger J, Stoppa A, Buchner R (2010) Molar conductivities and associationc of 1-butyl-3-methylimidazolium chloride and 1-butyl-3-methylimidazolium tetrafluoroborate in methanol and DMSO. J Chem Eng Data 55:1799-1803

10. Voroshylova IV, Smaga SR, Lukinova EV, Chaban VV, Kalugin ON (2015) Conductivity and association of imidazolium and pyridinium based ionic liquids in methanol. J Mol Liq 203:7-15

11. Katsuta S, Imai K, Kudo Y, Takeda Y, Seki H, Nakakoshi M (2008) Ion pair formation of alkylimidazolium ionic liquids in dichloromethane. J Chem Eng Data 53:1528-1532

12. Hunger J, Stoppa A, Buchner R (2008) From ionic liquid to electrolyte solution: dynamics of 1-N-butyl-3-N-methylimidazolium tetrafluoroborate/dichloromethane mixtures. J Phys Chem B 112: 12913-12919

12 Bešter-Rogač M, Hunger J, Stoppa A, Buchner R (2011) 1-Ethyl-3methylimidazolium ethylsulfate in water, acetonitrile, and dichloromethane: molar conductivities and association constants. J Chem Eng Data 56:1261-1267

14. Katsuta S, Shiozawa Y, Imai K, Kudo Y, Takeda Y (2010) Stability of ion pairs of bis(trifluoromethanesulfonyl)amide-based ionic liquids in dichloromethane. J Chem Eng Data 55:1588-1593

15. Bait S, Chattel GD, Kieviet WD, Tieleman A (1978) Ion association and solvation in dichloromethane of tetrachloro- and tetrabromoferrates(III) compared with simple halides. Z Naturforsch 33:745-749

16. Fuoss RM (1975) Conductance-concentration function for associated symmetrical electrolytes. J Phys Chem 79:525-540

17. Gestblom B, Songstad J (1987) Solvent properties of dichloromethane. 6. Dielectric properties of electrolytes in dichloromethane. Acta Chem Scand 41:396-409

18. Bešter-Rogač M, Habe D (2006) Modern advances in electrical conductivity measurements of solutions. Acta Chim Slov 53:391395

19. Boruń A, Bald A (2012) Conductometric studies of sodium tetraphenylborate, tetrabutylammonium bromide, and sodium tetrafluoroborate in $\mathrm{N}, \mathrm{N}$-dimethylformamide at temperatures from (283.15 to 318.15) K. J Chem Eng Data 57:2037-2043

20. Boruń A, Trzcińska I, Bald A (2014) Conductometric studies of sodium iodide, sodium tetraphenylborate, tetrabutylammonium iodide, and sodium tetrafluoroborate in 1-propanol at temperatures from (283.15 to 318.15) K. Int J Electrochem Sci 9:7805-7818 
21. Tôrres RB, Hoga HE (2008) Volumetric properties of binary mixtures of dichloromethane and amines at several temperatures and $\mathrm{p}=0.1 \mathrm{MPa}$. J Mol Liq 143:17-22

22. Su L, Wang H (2009) Volumetric properties of dichloromethane with aniline or nitrobenzene at different temperatures: a theoretical and experimental study. J Chem Thermodyn 41:315-322

23. Barthel MG, Krienke H, Kunz W (1998) Physical chemistry of electrolyte solutions: modern aspects. Springer, New York

24. Fuoss RM (1978) Conductance-concentration function for the paired ion model. J Phys Chem 82:2427-2440

25. Wang Y, Tremmel J, Smedt JD, Alsenoy CV, Geise HJ, Veken BV (1997) Ab initio determination of the force field of dichloromethane, verified by gas-phase infrared frequencies and intensities and applied to a combined electron diffraction and microwave investigation of geometry. J Phys Chem A 101:5919-5925

26. Riddick JA, Bunger WB, Sakano TK (1986) Organic solvents. Wiley, New York

27. Krestov GA, Afanas'ev VN, Efremova LS (1988) Fizikokhimicheskie svoistva binarnykh rastvoritelei (Physicochemical properties of binary solvents). Khimiya, Leningrad

28. Marcus Y, Hefter G (2006) Ion pairing. Chem Rev 106:4585-4621

29. Roy MN, Ray T, Roy MC, Datta B (2014) Subsistence of ion-pair and triple-ion origination of an ionic liquid, ([bmmim][BF4]) predominant in solvent systems. RSC Adv 4:62244-62254
30. Bešter-Rogač M, Stoppa A, Hunger J, Hefter G, Buchner R (2011) Association of ionic liquids in solution: a combined dielectric and conductivity study of [bmim $][\mathrm{Cl}]$ in water and in acetonitrile. Phys Chem Chem Phys 13:17588-17598

31. Gupta S, Chatterjee A, Das S, Basu B, Das B (2013) Electrical conductances of 1-butyl-3-propylimidazolium bromide and 1butyl-3-propylbenzimidazolium bromide in water, methanol, and acetonitrile at $(308,313$, and 318$) \mathrm{K}$ at $0.1 \mathrm{MPa}$. J Chem Eng Data 58:1-6

32. Sadeghi R, Ebrahimi N (2011) Ionic association and solvation of the ionic liquid 1-hexyl-3-methylimidazolium chloride in molecular solvents revealed by vapor pressure osmometry, conductometry, volumetry, and acoustic measurements. J Phys Chem B 115: 13227-13240

33. Roy MC, Roy MN (2014) Conductometric investigation of ionsolvent interactions of an ionic liquid $\left\{[\mathrm{emim}] \mathrm{CH}_{3} \mathrm{SO}_{3}\right\}$ in pure n-alkanols. J Mol Liq 195:87-91

34. Majdan-Cegincara R, Zafarani-Moattar MT, Shekaari H (2015) The study of solute-solvent interactions in 1-butyl-1methylpyrrolidinium trifluoromethanesulfonate+acetonitrile from solvent activity, density, speed of sound, viscosity, electrical conductivity and refractive index measurements. J Mol Liq 203:198203 